\title{
A Snapshot of High-Speed Broadband Responses at Local Government \\ Level in Australia: A Marriage between Federally Funded Initiatives and \\ Locally Driven Innovations?
}

Tooran Alizadeh and Heather Shearer

Urban Research Program, Griffith University

\begin{abstract}
The introduction of the Australian National Broadband Network (NBN) in 2009, posed a range of new questions about the potential of the telecommunication infrastructure for planning at different levels of government. This paper focuses on the local implications of the new infrastructure whether socio-economic, e-governance or otherwise. It reaches out to the NBN early rollout local government authorities (LGAs) and collects empirical data about their responses to the new infrastructure, so far. The findings explore the significant role of the federally funded initiatives aiming at the local level, while shedding light on some of the locally driven, mostly innovative approaches taken by the LGAs. The paper concludes by raising concerns about the current state of uncertainty around the future phases of broadband infrastructure rollout across the nation and its negative impact on strategic approaches in planning for and with telecommunication to capitalize on the digitally-driven opportunities.
\end{abstract}

\section{Keywords}

Local government, high-speed broadband, local planning, federal funding, local initiatives

\section{Introduction}

In response to shortcomings in Australia's telecommunication infrastructure (Barr, 2008; Given, 2008; Middleton, 2009; Middleton and Chang, 2008), the National Broadband Network (NBN) was announced in April 2009 to connect Australians to high-speed 
broadband (NBN Co. Ltd., 2010a). The rollout of the NBN on mainland Australia started one year later in March 2010 when NBN Co announced its five first release sites as part of live trials of the network design and construction methods (NBN Co. Ltd., 2010b). The trial phase continued over the following two years with the announcement of the second release sites, and the third release sites (a total of 60) where rollout would begin prior to September 2012 (NBN Co. Ltd., 2011, 2012a). Additionally, in March 2012, the first stage of large-scale rollout was released to provide NBN fibre to a third of the country containing over 3.5 million homes in 1500 communities (NBN Co. Ltd., 2012b). However, the result of the Federal election in 2013 completely changed the fate of the NBN rollout (NBN Co. Ltd., 2013).

Since its announcement, the NBN has been a highly political topic in Australia, influencing and being greatly influenced by the political setting (Given, 2008; Tucker, 2010). Perhaps the most pertinent example of this was when three independent MPs cited the NBN as one of the key reasons motivating their support for Labor over the Coalition following the hung parliament at the 2010 Federal election. On the other hand, following the 2013 Federal election, the change of the political setting proved a serious setback to the rollout of the NBN as the newly elected Coalition Federal Government decided to reassess the scale of the national fibre project, and put the first stage of the large-scale NBN rollout on hold. As of November 2013, only the 300,000 premises listed in the earlier rollout phases are guaranteed to be connected directly to the fibre network. The rest of the nation has to wait to learn about the details of their connection (Duke, 2013; Turner, 2013), despite the official statement by the new government insisting on the ongoing commitment to provide a nationwide telecommunication infrastructure network (NBN Co. Ltd., 2013).

This paper considers the current state as an opportunity to pose and analyse the efforts put into the national project over the last few years. It is perhaps time to acknowledge that despite the hefty 
investment on the NBN, there is still a dearth of evidence-based research to understand the socioeconomic implications of the new infrastructure particularly at the local planning level (Maeng and Nedovic-Budic, 2004). While the scope of the telecommunication infrastructure in the Australian context might change as a result of the ongoing assessment of the national project, this analysis will provide an opportunity for local planning to better engage with the telecommunication infrastructure, based on the lessons learned from the NBN early rollout.

The paper starts with a brief review of planning for broadband infrastructure in the international literature. This provides the foundation for the empirical part of the paper through which data is collected from the local government authorities (LGAs) involved with the NBN early rollout. The findings reveal an interesting diversity in the approaches taken at the local level, and shows how decision making at higher levels of government can impact local outcomes.

\section{Planning for Telecommunication (Broadband) Infrastructure}

Public infrastructure is portrayed as a powerful driver of economic growth and social prosperity (Aschauer, 1989; Button, et al., 1995; Gramlich, 1994; Seitz, 1995). More recently, planners have shown growing interest in broadband as the key telecommunication infrastructure (Eskelinena, et al., 2008; Ford and Koutsky, 2005). Over the last decade, several countries including the UK (Galloway, 2007), Korea (Kelly, et al., 2003; Speta, 2004), Germany (Katz, et al., 2010), Spain (Gerrand, 2006), US (Ford and Koutsky, 2005) and Finland (Eskelinena, et al., 2008) have undertaken substantial direct and indirect government investment in broadband infrastructure. Government involvement with telecommunication infrastructure is partly justified by the potential economic and social benefits of such infrastructure including increases in gross output, employment and aggregate consumption at national, regional and local levels (Alizadeh, et al., 2014; Lee, et al., 2005; Willson, et al., 2009).

In the Australian context, in August 2011, the Standing Committee on Infrastructure and 
Communications on behalf of the Parliament of Australia tabled its report on the potential of the NBN to enhance economic and regional development and social and community activity (Parliment of Australia, 2011). The report set forward a number of recommendations for the Australian Government including developing targeted programs for those currently disadvantaged by the digital divide. In other words, this report clearly shows that the Australian Government - similar to many international counterparts - has specific social and economic expectations from the rollout of the infrastructure.

Nevertheless, it is difficult and complex to establish that telecommunication infrastructure per se results in economic change (Lee, et al., 2005; Strategic Networks Group, 2003). More recently, a growing number of studies argue that broadband is a local issue (Grubesic, 2010), and its associated spatial outcomes should be integrated with local planning. A number of US-based studies have investigated the spatial landscape of broadband availability across the nation, noting that the geographic characteristics of broadband accessibility and opportunities remain uneven (Grubesic, 2004; Grubesic and Murray, 2004; Oyana, 2011). Research shows that a vast majority of locally driven municipal broadband initiatives and projects in the US complement private investment, fill gaps left by the federally funded initiatives and result in economic prosperity at the local level (Gillet, et al., 2004; Hauge, et al., 2008).

In the Australian context, there is a dearth of understanding when it comes to local implications of telecommunication infrastructure. It is not clear how the introduction of the NBN impacted on the local planning, and if there are any local differences in the range of possible implications. Issues such as the potential implications of the recent political decisions on the NBN for local governments are understudied and unclear. 
Methodology

This paper is part of a two-stage study focusing on the implications of telecommunication infrastructure at the local planning level in Australia. Stage 1 surveyed LGAs involved in the NBN early rollout. Contact officers from 59 LGAs were sent a short email survey to assess their involvement with the NBN rollout. The survey asked respondents about the importance of access to high speed broadband, the areas of council business most relevant to high speed broadband and how the council responded to the rollout of high speed broadband. A final question asked if the officers wished to take part in further research and be part of Stage 2. Those that indicated “yes" were interviewed over the telephone and their answers are analysed below.

Of the 59 LGAs sent the questionnaire survey, 26 replied, giving a 44\% response rate, which is consistent with response rates for online surveys (McNulty, 2008). Of the 26 responses, 17 indicated a desire to participate in follow-up interviews. Of these, a total of 10 officers were interviewed - four each from Queensland and New South Wales, one from Western Australia and one from Victoria. Two officers from Queensland, who were particularly proactive in their LGAs with regard to championing the NBN rollout, had a second follow-up interview (these are not counted in the number of interviews). The semi-structured interviews sought to gather more in-depth information about the implications of the NBN rollout in the LGAs concerned.

With the consent of the interviewees, all were recorded and transcribed into Microsoft Word and input into Nvivo (v10) software, which is specifically designed for qualitative data analysis and has a number of search, query and visualisation tools (Hughes, Lewins, \& Silver, 2010; QSR International, 2012). The analysis used the constant comparison approach, a form of inductive analysis, commonly used for text coding (Owens, 2012; Zhang \& Wildemuth, 2009; Glaser and Strauss, 1967). In this method, key words, paragraphs and phrases were 
categorised under "Nodes" (common themes in the interviews). Prior to the analysis, a set of draft themes based on the survey questions, and reflecting the literature (socio-economic development, e-governance, and spatial planning) were set up in NVivo. After detailed analysis of common words and phrases in the interview, the original themes were further refined in the analysis with the members of the project team, and merged into three overarching themes: Federally funded initiatives, Local Initiatives and champions, and Infrastructure. The final node hierarchy is shown in Table 1 and described in the Results below.

The ten interviewees, coming from the NBN early rollout LGAs, have all experienced a phenomenon that all LGAs across the nation will go through sooner or later. Although the speed and the technical details of Coalition's broadband are as yet, up to questions, the latest decision is to provide broadband infrastructure across Australia. Having said this, the interviews portray a snapshot of the major implications of the infrastructure rollout for the first release sites LGAs which could be useful for local planning for telecommunication infrastructure across the nation and beyond. This exploratory methodology could also set the foundation for further longitudinal studies to examine the local implications of the new infrastructure over the years to come.

\section{Results: What We Learned}

Following the node hierarchy approach in the interview analysis, the results are organised around the following overarching themes: 1) federally funded initiatives; 2) local initiatives and innovations; and 3) infrastructure: a serious disruption. Table 1 highlights the themes identified in the NVIVO coding process, which are further described below.

[Insert Table 1 near here] 


\section{Federally Funded Initiatives}

Following the introduction of the NBN in 2009, the Australian Federal Government introduced a range of funding initiatives aimed at different sectors of the society (businesses, households and local governments) to take advantage of the new infrastructure. This included three tranches of funding to local governments: the Digital Local Government Program; the Digital Enterprise Program; and the Digital Hubs Program (DBCDE, 2011). Many of the LGAs interviewed had successfully applied for grants in all three of these funding initiatives; indeed, many of the arrangements put into place to take advantage of NBN-based opportunities whether socio-economic or otherwise originated purely as a result of the federal funding initiatives. Nevertheless, it is important to note that across all interviewed LGAs, there was a sense of uncertainty as the majority of the federally finding initiatives are not going to be renewed under the new Coalition government, and the many of the interviewees believed that their local governments will not have the capacity to keep all of the programs running in the absence of ongoing federal funding.

\section{Digital Local Government Program}

The Digital Local Government (DLG) program, as part of the National Digital Economy Strategy, aimed to fund LGAs to provide innovative online services and to improve the quality, availability, and speed of their services (DBCDE 2011a). To date four funding rounds have been completed, with 48 LGAs having been granted this funding for initiatives such as online community engagement workshops, online emergency management systems and online development applications. Of those interviewed, six councils had been granted DLG funding.

Some criticism was aimed at the constraints of the fund; in particular, it was only offered to 
LGAs with the NBN and limited to videoconferencing. Most LGAs that had been granted this funding used videoconferencing with some innovative twists. For example one LGA, in collaboration with another council, offered videoconferencing in Arabic:

\footnotetext{
"We did some multi-language stuff with the video conferencing in Arabic in collaboration with Auburn council. We ran workshops on supporting family life etc. which was run from Auburn as they had the language capabilities to do it.”
}

Nonetheless, comments made during the interviews suggested that the focus on videoconferencing was due to the influence of external service providers and not due to the usefulness of the platform to LGAs.

\section{Digital Enterprise Program (DEP)}

An overarching theme of all interviews was the connection to businesses, particularly small to medium enterprises (SMEs) which is consistent with the literature (Shiels, et al., 2003; Taylor and Murphy, 2004). Of all business types, LGA officers considered that SMEs were amongst the most and least active internet users. For example, some interviewees, mostly those in "tree or sea change" LGAs, discussed how professionals such as web designers, had left the city and now worked, at least to some extent, from home, using fast broadband as a business platform. However, this was the exception rather than the norm. The majority of interviewees emphasized that most SMEs had an inadequate knowledge of how to use fast broadband to effectively promote, sell or manage the day to day aspects of their business. They saw a major difficulty in informing SMEs of the implications of not becoming informed about digital opportunities for efficiency and growth.

Of the three federally funded programs, the Digital Enterprise Program (DEP) aimed to provide free training and support for SMEs and not-for-profits to assist in the transition to deliver online services and products, to improve productivity, reach wider markets, 
effectively use social media, improve efficiency and use videoconferencing (DBCDE, 2011). The DEP funded group training courses and one-on-one mentoring sessions with local SMEs and NGOs, which were run either by the LGA or by local training providers, such as TAFEs (Australian providers of vocational education). Approximately $80 \%$ of the funding for this came from the federal government, with the balance provided by council. The DEP was rolled out to 69 communities around Australia. The syllabus for the training courses was based on the federal government website, digitalbusiness.gov.au and covered activities such as getting online, building a website, e-commerce, online marketing, cloud services and securities. The courses were popular - a Queensland-based LGA reported that approximately ten people attended each session, with about four sessions a month, for a period of 18 months. Another interviewee reported that they had held over 50 group training sessions and 220 individual sessions and had reached up to 400 individual organisations.

\section{Digital Hub Program}

An aspect of the business theme (although aimed at the general public as well as the business community) was the Digital Hub Program, which was rolled out in 40 communities with the aim of assisting local communities to increase their online engagement and better understand the opportunities of the digital economy (DBCDE, 2011). A range of services included training, access to high speed internet and videoconferencing were funded.

In practice, however, the Digital Hub program was interpreted differently across LGAs. The most common interpretation was to use council libraries as Digital Hubs, by providing free, fast broadband and sometimes digital literacy lessons for the community. One LGA used a library as a demonstration site for the applications and implications of high speed broadband. On the opposite end of the spectrum, some LGAs took Digital Hubs to mean full telecommuting facilities, working in collaboration with local businesses, governments and education providers to offer spaces whereby employees could work, at least part-time, and 
not have to commute to another LGA. This interpretation was common in large LGAs that were relatively close to capital cities such as Sydney, Brisbane and Melbourne. It was seen as advantageous to reduce commuting outside the LGA borders and keeping economic benefits locally.

\section{Local Initiatives and Innovations}

In addition to federally funded initiatives, available to all early rollout LGAs, our interviewees described a diverse range of locally driven innovative approaches taken during pre-rollout, construction and post-construction stages to take advantage of broadband-enabled opportunities.

\section{LGA “Champions”}

One of the most striking topics brought up in the interviews was the diverse levels of investment (numbers and type of personnel and time) that each LGA allocated to the NBN. Basically some could easily be described as LGA 'champions' because of the level of commitment during all three phases of pre-rollout, construction and post-construction. Moreover, some individual LGA officers were proactive in getting the NBN (and federally allocated funding) for their LGAs. Some interviewees told of extensive work that had been done prior to their LGA being nominated as an initial rollout site. Interviewees discussed a range of activities prior to and during the NBN rollout, such as collecting letters of support from businesses, lobbying government, allowing NBN Co use of site offices and storage facilities, entering into business partnerships with NBN Co and even becoming a licensed carrier and wholesaler network partner with Telstra and NBN Co. For example, one of the most active LGA champions from Queensland, said:

"We really started to get involved with the NBN after the announcement in April 2009. I led senior level discussions in our council regarding how we could take advantage of the 
NBN and how we could get it rolled out in our area sooner rather than later. The predominant reason being that we saw broadband as necessary infrastructure for supporting our rapid growth”.

Some of the approaches taken by LGA champions in their negotiations with the NBN Co were quite clever:

"Rather than simply focusing on the economic development aspect of NBN as most councils did, we saw NBN Co as an engineering company who would be primarily interested in how they would build the network in a cost effective manner. As such, we did a high level business case including mapping fibre optic back haul, key council facilities for fibre exchanges, identified areas of black spots lacking decent fixed line broadband and identified areas where council workforce and depots could be used. This was put together to give NBN Co some baseline information that they could use in the initial stages of the rollout.”

However, in some cases, no matter how little investment the LGA put towards the NBN, it was still rewarded reflecting the political environment of the time. For example, one officer, when asked what they had done to be part of the NBN rollout, replied that an Independent MP, who partly held the balance of power in government, was their local member. Another interviewee stated that their LGA was a swinging marginal seat (in an area that often plays a major role in political lobbying) and the then Prime Minister had attended the launch of their digital strategy. Conversely, despite putting in extensive work, others were unsuccessful and their efforts were not rewarded with any significant rollout. For example, a couple of interviewees mentioned the Sunshine Coast as one of the most striking omissions, which not only lobbied extensively, but also was instrumental in forming the Broadband Today Alliance. Arguably, this reflected the area’s status as a "safe liberal seat” (at the time). 


\section{Council Collaboration}

When taking advantaging of what broadband infrastructure can offer at the local level, LGAs reported varying degrees of collaboration with other councils to raise awareness within their local community, prepare digital strategies and even putting forward business cases for the NBN. The most common version of council collaboration referred to the Broadband Today Alliance (BTA) which is a collaborative alliance of local government, RDA and Regional Organisations of Councils (ROCs) initiated by Sunshine Coast Council (Sunshine Coast Regional Council, 2012), built on the premise of sharing information and advocating for the resources to assist the localised transition to a digital economy. Over 135 local governments are members with over eight million Australians represented.

Some of the interviewees from LGAs in urban or peri-urban areas reported varying degrees of informal collaboration, such as attending regional development groups, working on varying digitally-driven projects with other councils including Smart eDA, which was aimed to move planning and development assessment to an online platform, with a number of councils. In general, the LGAs that entered into these agreements were in New South Wales and Victoria where a many smaller councils comprise the metropolitan areas of Sydney and Melbourne.

\section{Innovations}

During the interviews a range of locally driven innovations were discussed, which were adopted by LGAs to facilitate communication and land use planning via digitally enabled opportunities.

Communication: Communication was a recurring theme in all interviews and included discussions around barriers, public demand and social networking. Most interviewees emphasized the importance of communication with the public, businesses or within council 
itself. A number of digitally-enabled methods of communication were used by LGAs including information on the council website, the use of social media such as Facebook and Twitter and videoconferencing. LGAs had a wide interpretation of what constituted communication including: full public participation in Council meetings via videoconferencing; the ability to complete LGA forms online; and a step-by-step guide on the council website about what permissions they needed to run a business. However, most of discussions around digitally-enabled communication were in line with Williamson \& Parolin (2012), with LGAs largely engaging in monologue communication. Some encouraging trends were apparent however, with larger LGAs investigating the use of smart phone technology and increased use of social media. For example, one interviewee stated:

\footnotetext{
"Our communications team maintains our social media interaction with the community including Facebook and Twitter. For example if there was a water main break, these feeds would post regular updates on council's response and when normal services resume.”
}

In general however, even using the more innovative methods, the type of communication was firmly controlled by the LGA, with social media comments strictly moderated, and noninteractive videos posted after council meetings.

Land use planning: Some interviewees discussed how the NBN might impact on land-use planning including online access to development applications (DAs) and various issues around community complaints about mobile telephone towers. The degree to which broader land use planning data was available online was quite varied. For example, some of the larger Queensland LGAs have sophisticated online information, including maps of planning schemes, free downloadable data such as cadastre, the ability to apply and search for development applications, etc. Whereas in other states (i.e. Western Australia), this 
information was not easily available, and if so, only in pdf form or is available but only on a paid basis (i.e. New South Wales and Victoria).

With regard to developments, the public could access a range of information, such as the status of an application, online lodgement of DAs, mapping of constraint layers for potential developments, etc. This however was seen as driven largely by the state (and notable differences existed between states in what information was available online) and a Federal housing affordability program which gave \$30 million in funding to LGAs around the country, based on their proportion of new houses, to promote eDA (electronic development assessment) initiatives (Williamson \& Parolin, 2012). When LGAs implemented eDA, it was usually successful, and well supported by council, developers and the public. As stated by several council officers, a lot of work had been done to facilitate land development via digitally-enabled solutions, but there was still room for improvement, particularly around the lodgement process. One innovative LGA was developing a mobile phone application which was a "land database aggregator. This combines a variety of land sources into one location for ease of access to local land information for investors, developers and business people”. This was also used to give information on changes in land availability, types of available opportunities and even historical information about an area.

Another issue related to infrastructure, leading on to land-use planning, were problems around planning for mobile phone infrastructure, in particular, mobile phone towers. It was stated several times during the interviews that "the community demands mobile phone and wireless services, but is not willing to have the infrastructure in their backyards”. A common complaint was the lack of transparency around the NBN rollout, in that only one of the LGAs interviewed had access to geographic information systems (GIS) layers of the NBN rollout, and even fewer on actual infrastructure, even in some cases where the council allowed NBN Co to use their existing infrastructure, and changed their planning schemes to adhere to the 
telecommunications act that requires developers to install fibre-optic cable for all developments above a certain size.

\section{Infrastructure: A Serious Disruption}

The main themes discussed in the interviews can be categorised around two broad categories: federally funded initiatives; and local initiatives and innovations. However, infrastructure with a focus on the NBN rollout was brought up repeatedly in all interviews as a major disruption. Part of the disruption came from within the local community, as some LGAs found working with parts of the more traditional business community quite difficult. For example, a LGA wished to introduce Wi-Fi into a certain area and despite the support of the local businesses, this was not shared by the businesses' landlords. Because of the requirement that businesses must obtain the landlord's permission to install the Wi-Fi systems, the project had stalled. However, the biggest disruption was described with reference to the NBN rollout plan, and more specifically the recent political decision to reassess the whole national project. The differences between the ALP NBN and the Coalition NBN were discussed in some of interviews:

"The original, and significantly more expensive ALP proposal was primarily engaged in rolling out FTTP to the majority of houses, but the Coalition's NBN involves a multitechnology mix of broadband infrastructure: (FTTP- fibre to the premise; FTTN- fibre to the node; fibre to the basement; fibre to the drop point and HFC (pay TV) cable).”

Interviewees mostly considered that the recent decision could result in uneven and patchy access around the LGAs, and even create an access divide, with potential socio-economic impacts, for example on property prices. For example one Queensland interviewee commented:

"A lot of work was put into lobbying and cooperating with the city, then there was a lot of frustration with the lack of information coming from NBN Co and the federal policy 
was very patchy with small communities connected with the NBN and everyone around them lacking the connection.”

Another interviewee stated that in their LGA, some key areas such as parts of the CBD were not included in the early rollout, and now are going to miss the highest speed 'forever'.

\section{Conclusion}

The paper is part of a two-stage study that engaged LGAs involved with the early rollout of the NBN to learn about the local implications of the new infrastructure. The results confirm the significant role of Australian Federal Government through the major direct investment on the infrastructure, and development of locally targeted initiatives as part of the national strategies to guide the implications of telecommunication infrastructure. However, a range of locally driven initiatives and innovations allowed local communities to take advantage of digitally driven opportunities. Last but not least, the current state of uncertainty around the future phases of the national broadband network, has put a lot of pressure on local governments.

This analysis of the forerunner LGAs provides a snapshot of the major concerns experienced by the early infrastructure rollout, and presents initiatives and innovations taken to capitalize on the digitally-driven opportunities. Nevertheless, it is recommended that this preliminary scoping study needs to be followed up with further longitudinal investigations as the infrastructure unfolds. 


\section{References}

Alizadeh, T., Sipe, N., and Dodson, J., 2014. Spatial planning and high speed broadband: Australia's national broadband network and metropolitan planning. International Planning Studies, DOI: 10.1080/13563475.2014.965248.

Aschauer, D. A., 1989. Is public expenditure productive? Journal of Monetary Economics 23(2), 177-200.

Barr, T., 2008. Broadband bottleneck: History revisited. Media International Australia, 129(Nov), 129-139.

Button, K. J., Leitham, S., McQuaid, R. W., and Nelson, J. D., 1995. Transport and industrial and commercial location. Annals of Regional Science, 29(2), 189-206.

DBCDE, 2011. National digital economy strategy. Canberra: Australian Government, Department of Broadband Communications Digital Economy.

Duke, J., 2013. 900,000 premises may need to foot bill under nbn revision Melbourne: Property Observer. Retrieved 19 Nov, 2013, from http://www.propertyobserver.com.au/news/900000-premises-may-need-to-foot-billunder-nbn-revision-archers/2013111466370

Eskelinena, H., Frankb, L., and Hirvonena, T., 2008. Does strategy matter? A comparison of broadband rollout policies in finland and sweden. Telecommunications Policy, 32(6), 412-421.

Ford, G. S., and Koutsky, T. M., 2005. Broadband and economic development: A municipal case study from florida Review of Urban \& Regional Development Studies, 17(3), 216-229. 
Galloway, L., 2007. Can broadband access rescue the rural economy? Journal of Small Business and Enterprise Development, 14(4), 641-653.

Gerrand, P., 2006. Accelerating broadband rollout - initiatives in regional spain.

Telecommunications Journal of Australia, 56(3/4), 84-89.

Gillet, S., Lehr, W., and Osorio, C., 2004. Local government broadband initiatives. Telecommunications Policy, 28(7-8), 537-558.

Given, J., 2008. Australia's broadband: How big is the problem? Media International Australia, 127(May), 6-10.

Gramlich, E. M., 1994. Infrastructure investment: A review essay. Journal of Economic Literature, 32(3), 1176-1196.

Grubesic, T. H., 2004. The geodemographic correlates of broadband access and availability in the united states Telematics and Informatics, 21(4), 335-358.

Grubesic, T. H., 2010. Efficiency in broadband service provision: A spatial analysis. Telecommunications Policy, 34(3), 117-131.

Grubesic, T. H., and Murray, A. T., 2004. Waiting for broadband: Local competition and the spatial distribution of advanced telecommunication services in the united states. Growth and Change, 35(2), 139-165.

Hauge, J., Jamison, M., and Gentry, R., 2008. Bureaucrats as entrepreneurs: Do municipal telecommunications providers hinder private entrepreneurs? Information Economics and Policy, 20(1), 89-102.

Katz, R. L., Vaterlaus, S., Zenhäusern, P., and Suter, S., 2010. The impact of broadband on jobs and the german economy. Intereconomics, 45(1), 26-34. 
Kelly, T., Gray, V., and Minges, M., 2003. Broadband korea: Internet case study. Seoul: International Telecommunications Union.

Lee, H., Oh, S., and Shim, Y., 2005. Do we need broadband? Impacts of broadband in korea. info, 7(4), 47-56.

Maeng, D.-M., and Nedovic-Budic, Z., 2004. Chicago and seoul: A comparative study of the impact of information and communications technologies on urban land use and regulation. Journal of Urban Technology, 11(2), 61-92.

Middleton, C., 2009. Can broadband support environmental sustainability?

Telecommunication Journal of Australia, 59(1), 10.11-10.14.

Middleton, C., and Chang, S., 2008. The adoption of broadband internet in australia and canada. In: Y. K. Dwivedi, A. Papazafeiropoulou, andJ. Choudrie, eds. Handbook of research on global diffusion of broadband data transmission. Harrisburg, PA: IGI Global, 820-842.

NBN Co. Ltd., 2010a. Corporate plan 2011 - 2013. Canberra: NBN Co. Ltd.

NBN Co. Ltd., 2010b. Nbn co announces "first release" sites for high-speed network Melbourne: NBN Co. Ltd. Retrieved 12 Feb, 2012, from http://www.nbnco.com.au/news-and-events/news/nbn-co-announces-first-releasesites-for-high-speed-network.html

NBN Co. Ltd., 2011. Nbn co releases 12-month national rollout plan Melbourne: NBN Co. Ltd. Retrieved 12 Feb, 2012, from http://www.nbnco.com.au/news-andevents/news/nbn-co-releases-12-month-national-rollout-plan.html

NBN Co. Ltd., 2012a. Nbn co announces next rollout locations Melbourne: NBN Co. Ltd. Retrieved 12 Feb, 2012, from http://www.nbnco.com.au/news-and-events/news/nbnco-announces-next-rollout-locations.html 
NBN Co. Ltd., 2012b. Three year rollout plan for nbn announced Melbourne: NBN Co. Ltd.,. Retrieved 12 Dec, 2012, from http://www.nbnco.com.au/news-and-events/news/nbnco-announces-three-year-rollout-plan.html

NBN Co. Ltd., 2013. Detailed data and updated website maps open up australia’s largest infrastructure project to more transparency Melbourne: NBN Co. Ltd. Retrieved 19 Nov, 2013, from http://www.nbnco.com.au/about-us/media/news/weekly-rollout$\underline{\text { metrics.html }}$

Oyana, T. J., 2011. Exploring geographic disparities in broadband access and use in rural southern illinois: Who's being left behind? Government Information Quarterly, 28(2), 252-261.

Parliment of Australia, 2011. Broadening the debate : Inquiry into the role and potential of the national broadband network Canberra: House of Representatives, Standing Committee on Infrastructure and Communications.

Seitz, H., 1995. The productivity and supply of urban infrastructures. Annals of Regional Science, 29(2), 121-141.

Shiels, H., McIvor, R., and O'Reilly, D., 2003. Understanding the implications of ict adoption: Insights from smes. Logistics Information Management, 16(5), 312 - 326.

Speta, J. B., 2004. Commentary: Policy levers and demand drivers in korea broadband penetration. Journal of Korean Law, 4(1), 1-18.

Strategic Networks Group, 2003. Economic impact study of the south dundas township fibre network. London: Department of Trade and Industry (DTI). Retrieved 15 April, 2011 from www.berr.gov.uk/files/file13262.pdf.

Sunshine Coast Regional Council, 2012. Broadband today Sunshine Coast: Broadband Today Alliance. Retrieved 25 June 2012, from http://www.broadbandtoday.com.au/about 
Taylor, M., and Murphy, A., 2004. Smes and e-business. Journal of Small Business and Enterprise Development, 11(3), 280 - 289.

Tucker, R. S., 2010. Broadband facts, fiction and urban myths. Telecommunications Journal of Australia, 60( 3), 1-15.

Turner, A., 2013. Nbn hookups put on hold Sydney: Sydney Morning Herald. Retrieved 19 Nov 2013, from http://www.smh.com.au/digital-life/digital-life-news/nbn-hookupsput-on-hold-20131106-2wzz4.html

Willson, P., Marshall, P., and McCann, J., 2009. Evaluating the economic and social impact of nbn. Paper presented at the 20th Australasian Conference on Information Systems, Melbourne. 
Tables and Figures

Table 1. Node Hierarchy

\begin{tabular}{|c|c|}
\hline Name & References \\
\hline Federal Funding & 11 \\
\hline - Digital Enterprise & 9 \\
\hline - Digital Hubs & 7 \\
\hline o Public IT upskilling & 3 \\
\hline o Teleworking & 9 \\
\hline - Digital Local Government & 0 \\
\hline o E-Governance & 7 \\
\hline o Videoconferencing & 3 \\
\hline Infrastructure & 11 \\
\hline - Development Applications & 6 \\
\hline - Land-use planning & 7 \\
\hline o Footprint size \& Rollout & 7 \\
\hline o Spatial and zoning & 4 \\
\hline - NBN Technology & 7 \\
\hline o Partnerships with NBN Co & 5 \\
\hline Local Initiatives and Innovations & 11 \\
\hline - $\quad$ Champions & 6 \\
\hline - Council collaboration & 9 \\
\hline o Business & 7 \\
\hline o Competiveness & 3 \\
\hline o Council changes from NBN & 4 \\
\hline o Governance & 3 \\
\hline - Innovation & 0 \\
\hline
\end{tabular}

